Reprod. Nutr. Dévelop., 1985, 25 (3), 591-598.

\title{
Influence de la concentration des précurseurs dans la biosyn- thèse de la testostérone par le testicule embryonnaire de Poulet.
}

\author{
J.-P. WENIGER, L. FAY(*), J. CHOURAQUI, A. ZEIS
}

Laboratoire de Zoologie et d'Embryologie expérimentale, Université Louis-Pasteur

12, rue de l'Université, 67000 Strasbourg, France.

(*) Laboratoire de Biochimie médicale

Faculté de Médecine, INSERM U. 208

2, boulevard Jeanne-d'Arc, 21033 Dijon, France

Summary. Influence of precursor concentration on the biosynthesis of testosterone by the chick embryo.

The aim of this study was to determine whether substrate concentration was of crucial importance in the formation of testosterone by the chick embryo testis.

Testes from 15 to 18-day old chick embryos were cultured in medium 199 with dehydroepiandrosterone $1,2,6,7-{ }^{3} \mathrm{H}$ or androstenedione $-4-{ }^{14} \mathrm{C}$ added at different concentrations. Testosterone was identified and measured by crystallization to constant specific activity or by gas chromatography-mass spectrometry. The formation of testosterone could not be demonstrated at a substrate concentration of $76 \mathrm{nM}$. Concentrations in the micromolar range yielded measurable quantities of testosterone which increased to about $10 \%$ of the added substrate when the concentration was $70 \mu \mathrm{M}$. However, the capacity to form testosterone was shared by other organs such as the ovary or the mesonephros.

These results should settle definitively the question concerning the formation of testosterone by the chick embryo testis. When exposed to high substrate concentrations, the testis can form testosterone, but under physiological conditions there is no such testosterone formation. This conclusion is in agreement with the absence of any physiological role of testosterone in the chick embryo.

\section{Introduction.}

Si la sécrétion de testostérone par le testicule embryonnaire est un fait certain chez les Mammifères, la question est encore débattue chez les Oiseaux. Pour nous en tenir aux toutes dernières publications, Guichard et a/. (1979) ont trouvé par dosage radio-immunologique, après culture de testicules embryonnaires de Poulet sur des milieux additionnés de déhydroépiandrostérone ou d'androstènedione à forte concentration (86-87 $\mu \mathrm{M})$, de grandes quantités de testostérone dans ces milieux. Par contre, cultivant les testicules en présence de déhydroépian- 
drostérone ou d'androstèdione tritiées de forte activité spécifique, c'est-à-dire sur des milieux faiblement concentrés en ces substances (20-30 nM), Weniger et al. (1984) n'ont pas pu démontrer la formation de testostérone tritiée par dilution isotopique. En rapprochant ces deux résultats, on pouvait s'interroger sur l'importance de la concentration en substrat. Les résultats exposés dans le présent travail démontrent clairement cette importance, mettant par là même un terme au débat sur la formation de testostérone par le testicule embryonnaire de Poulet.

\section{Matériel et méthode.}

Les embryons de Poulet utilisés étaient de race Leghorn blanche et avaient entre 15 et 18 jours d'incubation. Testicules, ovaires gauches et mésonéphros, découpés en fragments, furent cultivés in vitro dans des boîtes de Pétri pour culture d'organes "Falcon » sur le milieu 199 additionné de déhydroépiandrostérone ${ }^{3} \mathrm{H}-1,2,6,7$ (Amersham) ou d'androstènedione-4- ${ }^{14} \mathrm{C}$ (Amersham) à différentes concentrations. $700 \mu \mathrm{l}$ de milieu de culture remplissaient la logette centrale de la boîte de Pétri et affleuraient une grille en acier inoxydable recouverte d'un disque de papier filtre "Durieux " que le liquide imbibait et sur lequel étaient placés les fragments d'organes. L'incubation était faite à $37^{\circ} \mathrm{C}$ pendant $24 \mathrm{~h}$ dans une atmosphère enrichie en oxygène et en gaz carbonique.

Au terme des $24 \mathrm{~h}$ de culture, le milieu fut recueilli et les fragments d'organes furent rincés deux fois avec $500 \mu \mathrm{l}$ de liquide de Tyrode qui furent ajoutés aux $700 \mu \mathrm{l}$ de milieu. Milieu et liquides de rinçage réunis, additionnés ou non de $100 \mu \mathrm{g}$ de testostérone non radioactive en tant qu'entraîneur, furent extraits par $30 \mathrm{ml}$ du mélange éther éthylique-dichlorométhane 3:1. Après évaporation des solvants, les extraits furent soit traités directement par les réactifs de silylation en vue de leur analyse par chromatographie en phase gaz-liquide, couplée à la spectrométrie de masse, soit soumis à une chromatographie sur couche mince de gel de silice, suivie de la détermination de la testostérone par dilution isotopique. A cette fin, la testostérone isolée lors de la chromatographie de l'extrait total a été acétylée, l'acétate de testostérone a été chromatographié à son tour, puis recristallisé à activité spécifique constante selon la méthode décrite antérieurement (Weniger et al., 1984). Pratiquement totale après simple extraction, la récupération tombe à $82,45 \pm 4,76 \%(n=11)$ après acétylation et la double chromatographie. Les quantités de testostérone trouvées ont été corrigées pour une récupération totale.

\section{Résultats.}

1. Dilution isotopique. - Les figures 1 et 2 montrent les radiochromatogrammes de la fraction " acétate de testostérone " se rapportant aux expériences 1 et 2. Dans l'expérience 1, où la concentration de la déhydroépiandrostérone était $76 \mathrm{nM}$, la bande d'acétate de testostérone repérée aux rayons UV est dénuée d'activité. Dans l'expérience 2 par contre, où cette concentration était $70 \mu \mathrm{M}$, un pic de radioactivité lui correspond. 


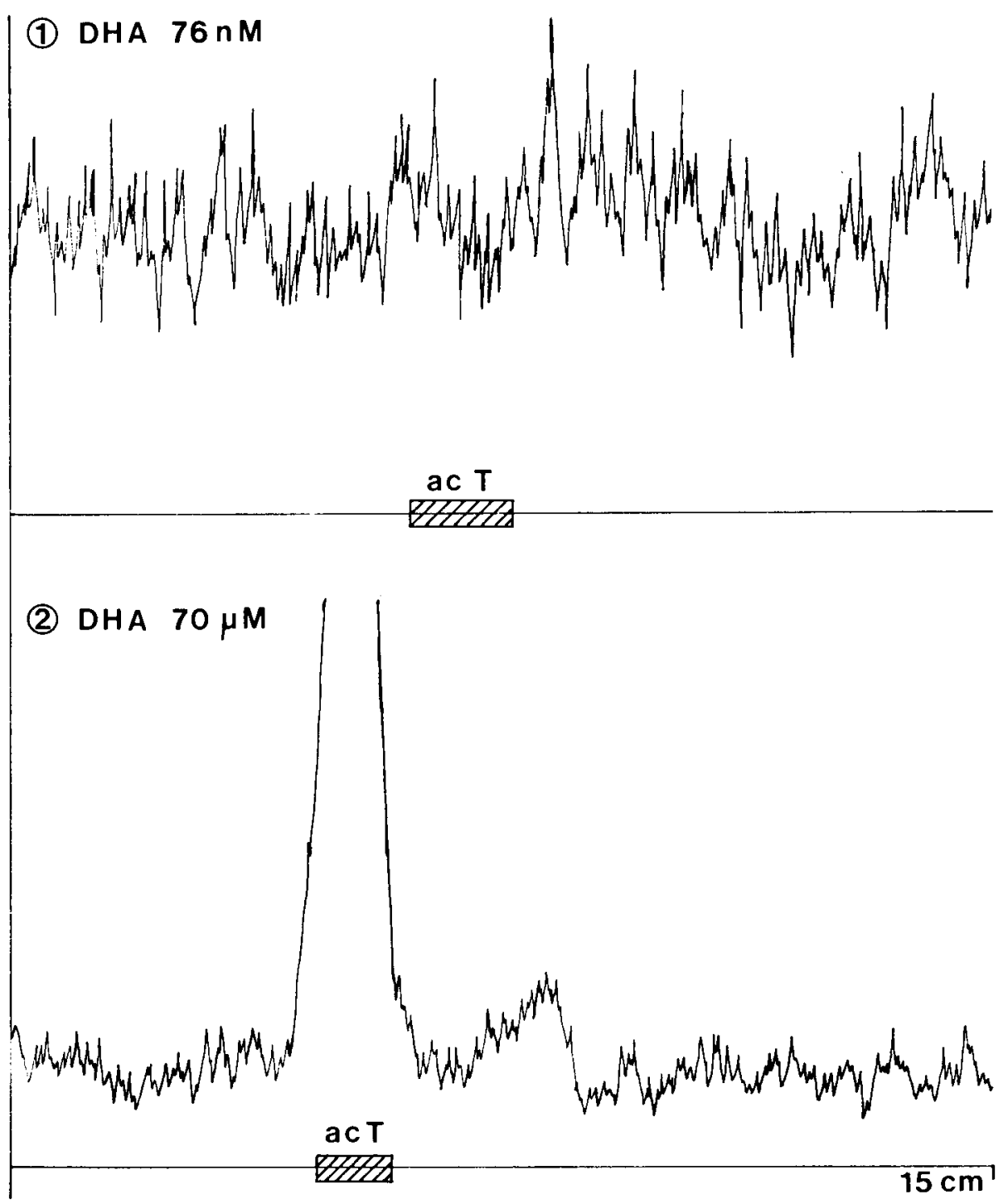

FIG. 1 et 2. - Radiochromatogrammes de la fraction "acétate de testostérone " se rapportant aux expériences 1 et 2. Explications dans le texte.

Le tableau 1 contient des exemples d'identification de la testostérone par recristallisation à activité spécifique constante et indique le mode de calcul du pourcentage de transformation.

Le tableau 2 donne à la fois le détail des conditions expérimentales et les résultats finaux. Ceux-ci donnent lieu aux observations suivantes. 
A partir de déhydroépiandrostérone à la concentration $76 \mathrm{nM}$, la synthèse de testotérone par les testicules n'était pas démontrable. Par contre, aux deux autres concentrations essayées, 7 et $70 \mu \mathrm{M}$, cette synthèse a lieu comme elle a lieu à partir d'androstènedione $12 \mu \mathrm{M}$. Mais cette synthèse de testostérone n'est pas spécifique des testicules. Elle est aussi effectuée par l'ovaire et le mésonéphros ; elle semble même plus importante dans ces organes que dans les testicules. Mais il faut faire remarquer que si la masse d'un ovaire gauche équivaut en gros à celle d'une paire de testicules, la masse des deux mésonéphros est certainement supérieure. Que la quantité de testostérone formée ait été plus faible à partir d'androstènedione $12 \mu \mathrm{M}$ (expérience 7) que de déhydroépiandrostérone $7 \mu \mathrm{M}$

TABLEAU 1

Exemples d'identification de la testostérone par recristallisation à activité spécifique constante et détermination du pourcentage de transformation.

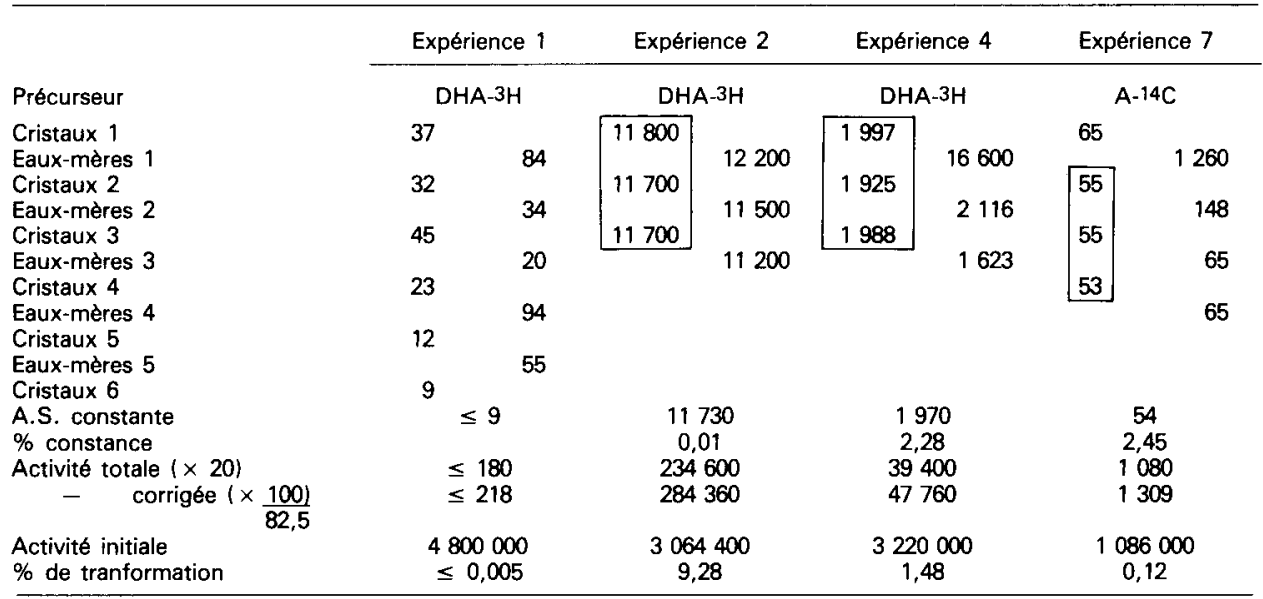

Activité spécifique (A.S.) des cristaux et des eaux-mères exprimée en coups $/ \mathrm{min} / \mathrm{mg}$. Les valeurs constantes sont encadrées. Quantité d'entraîneur ajoutée : $20 \mathrm{mg}$. DHA : déhydroépiandrostérone ; $A$ : androstènedione. Le rendement du comptage du $3 \mathrm{H}$ était de $33 \%$, celui du $14 \mathrm{C}$ de $60 \%$.

TABLEAU 2

Conditions expérimentales et quantités de testostérone (T) formées à partir de déhydroépiandrostérone- ${ }^{3} \mathrm{H}$ ou $d^{\prime}$ androstènedione- ${ }^{14} \mathrm{C}$.

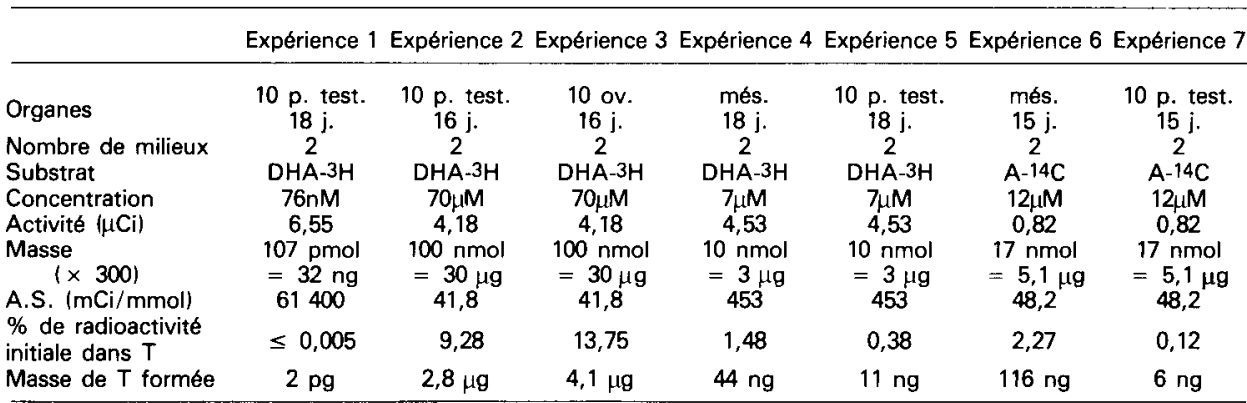




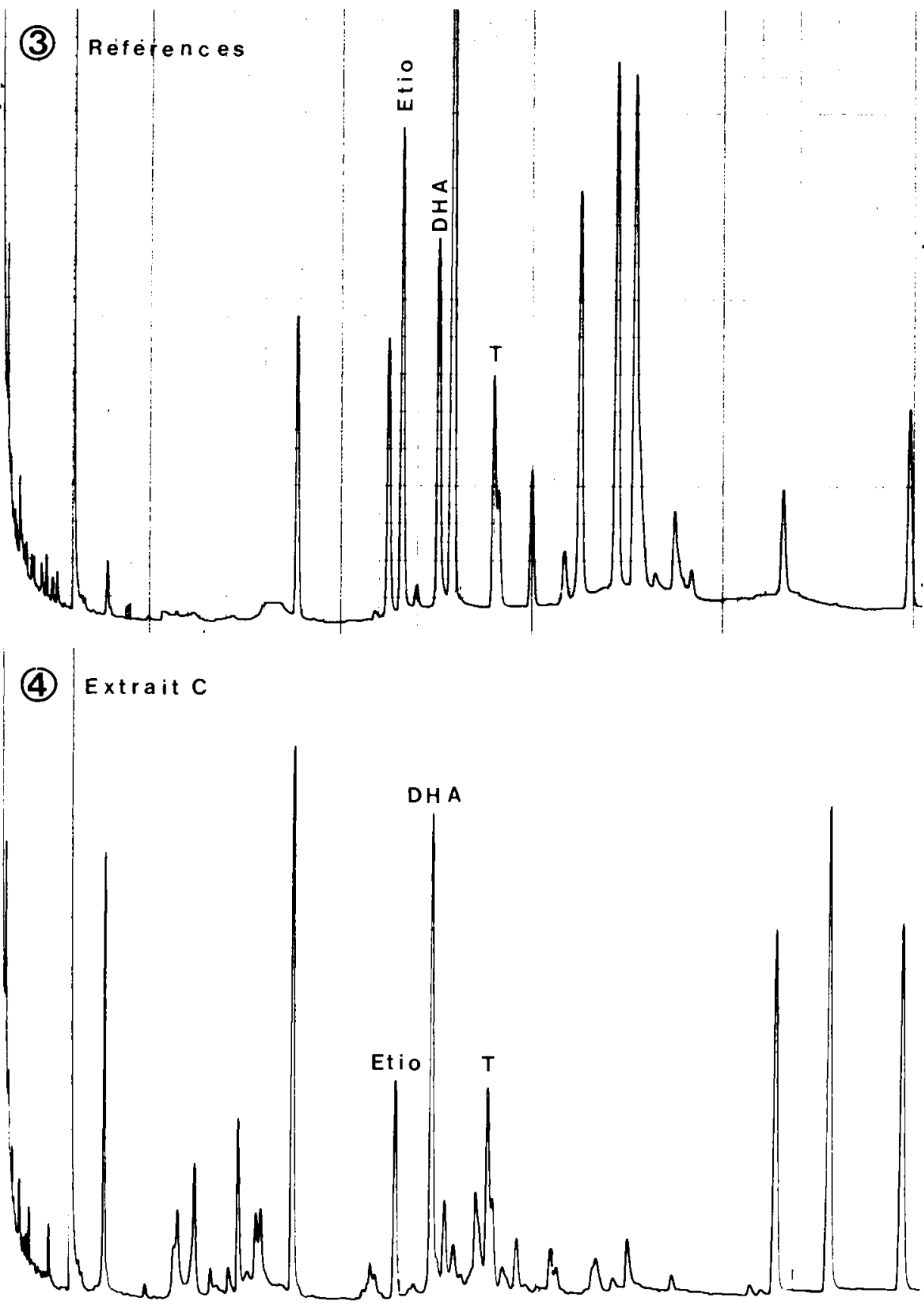

FIG. 3 et 4. - Chromatogrammes en phase gaz-liquide sur colonne capillaire OV-1 d'un mélange de substances de référence (fig. 3) et de l'extrait $C$ (fig. 4) après formation de derivés méthyloxime - éther de triméthy/sily/e. Le pic caractéristique de la testostérone se retrouve sur le chromatogramme de l'extrait. Etio : étiocholanolone. 


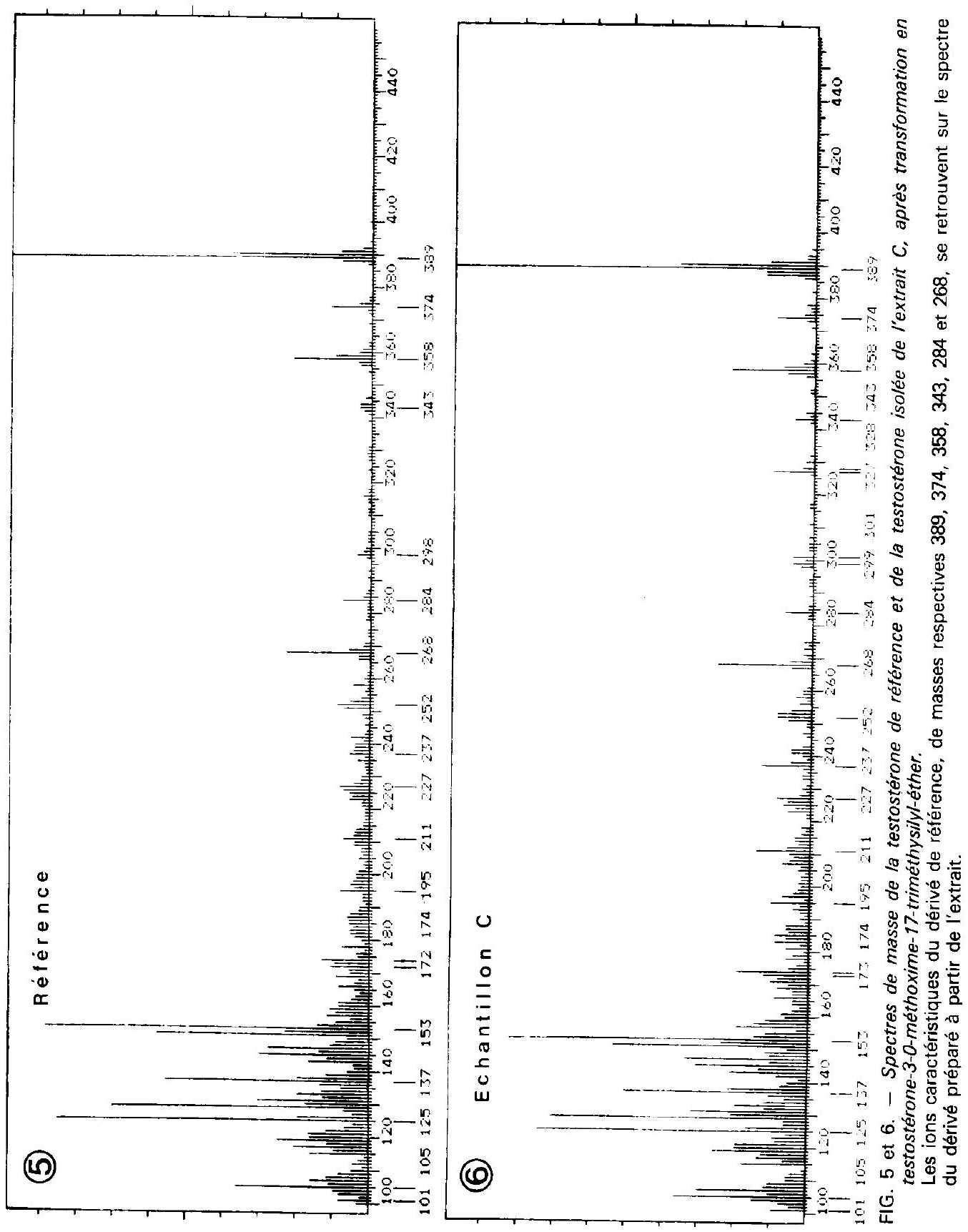


(expérience 5) peut s'expliquer par la différence d'âge des testicules dans les deux expériences. A l'inverse, le mésonéphros étant encore plus développé à 15 jours qu'à dix-sept, on comprend que la formation de testostérone soit plus importante à 15 jours.

2. Chromatographie en phase gazeuse-spectrométrie de masse. - La comparaison des figures 3 et 4 , représentant les chromatogrammes d'un mélange de substances de référence (fig. 3) et de l'extrait $C$ (fig. 4), permet de reconnaître la présence de testostérone dans l'extrait. Parmi les autres composés formés en quantité importante figure l'étiocholanolone (5 $\beta$-androstane-3 $\alpha$-ol-17-one). L'identité de la testostérone est confirmée par son spectre de masse (fig. 5 et 6).

Les quantités de testostérone présentes dans les 2 échantillons analysés par chromatographie sont indiquées dans le tableau 3. La concordance avec les valeurs obtenues par dilution isotopique dans les expériences 2 et 3 (tabl. 2) est satisfaisante.

TABLEAU 3

Quantités de testostérone trouvées par chromatographie en phase gaz-liquide sur colonne capillaire ov-1.

\begin{tabular}{lcc}
\hline & Echantillon B & Echantillon C \\
\hline Organes & 10 ov. $18 \mathrm{j}$. & $10 \mathrm{p}$. test. $18 \mathrm{j}$. \\
Nombre de milieux & 2 & 2 \\
Substrat & DHA & DHA \\
Concentration $(\mu \mathrm{M})$ & 70 & 70 \\
Masse $(\mu \mathrm{g})$ & 30 & 30 \\
Masse de T formée $(\mu \mathrm{g})$ & 4,25 & 4,7 \\
$\%$ de transformation & 14,2 & 15,7 \\
\hline
\end{tabular}

\section{Discussion.}

Ce qu'il convient de retenir des résultats qui viennent d'être exposés, c'est qu'il faut une concentration minimale en substrat, environ $1 \mu \mathrm{M}$, qu'il s'agisse de déhydroépiandrostérone ou d'androstènedione, pour que la formation de testostérone par les testicules embryonnaires de Poulet puisse être mise en évidence. Mais cette capacité de formation de testostérone n'est pas l'apanage des testicules ; elle est partagée par d'autres organes, nommément l'ovaire et le mésonéphros. C'est dire que la $17 \beta$-hydroxystéroïde-déshydrogénase, ainsi que le système enzymatique $\Delta_{5}$-3 $\beta$-hydroxystéroïde-déshydrogénase, $\Delta_{4}-\Delta_{5}$-isomérase, existent dans tous ces organes. Mais il faut une forte concentration en substrat pour que les réactions catalysées par ces enzymes aboutissent à la formation de testostérone. 


\section{Conclusion.}

En soulignant l'importance de la concentration en substrat, les résultats du présent travail devraient clore le débat sur la formation de testostérone par le testicule embryonnaire de Poulet. Celle-ci est possible en présence de fortes concentrations en substrat, mais inexistante dans les conditions physiologiques. On rappellera qu'il n'a pas été possible de démontrer la synthèse totale de testostérone à partir d'acétate de $\mathrm{Na}$ (Weniger, 1969 ; Guichard et al., 1973), ni de mettre en évidence, par des expériences d'associations d'organes en culture in vitro, une action du testicule embryonnaire de Poulet sur des organes effecteurs de la testostérone, tels le canal de Wolff d'embryon de Souris ou le canal de Wolff d'embryon de Poulet (Weniger, 1965 ; Chouraqui et al., 1980).

Reçu en décembre 1984. Accepté en février 1985.

\section{Références}

CHOURAQUI J., ZEIS A., WENIGER J.-P., 1980. Etude comparative en culture in vitro de l'action des testicules embryonnaires de Poulet et de Rat sur le canal de Wolff d'embryon de Poulet. Arch. Anat. micr. Morph. exp., 69, 167-173.

GUICHARD A., CEDARD L., HAFFEN K., 1973. Aspect comparatif de la synthèse de stéroïdes sexuels par les gonades embryonnaires du Poulet à différents stades du développement (étude en culture organotypique à partir de précurseurs radioactifs). Gen. comp. Endocrin., 20, 16-28.

GUICHARD A., CÉDARD L., MIGNOT Th.-M., SCHEIB D., HAFFEN K., 1979. Radioimmunoassay of steroids produced by chick embryo gonads cultured in presence of some exogenous steroid precursors. Gen. comp. Endocrin., 39, 9-19.

WENIGER J.-P., 1965. Etude comparée des actions hormonales des testicules embryonnaires de Poulet et de Souris en culture in vitro. Arch. Anat. micr. Morph. exp., 54, 909-919.

WENIGER J.-P., 1969. Recherches sur la nature chimique des hormones sexuelles embryonnaires de Poulet. Ann. Embr. Morph., 6, 219-228.

WENIGER J.-P., CHOURAQUI J., ZEIS A., 1984. Le problème de la sécrétion de testostérone par le testicule embryonnaire de Poulet: nouvelles recherches. Reprod. Nutr. Dévelop., 24, 155-164. 